\title{
LUNG CANCER TRENDS IN SOUTHEASTERN SERBIA
}

\author{
Biljana Kocić ${ }^{1,2}$, Branislav Petrović ${ }^{1,2}$, Nataša Rančić ${ }^{1,2}$, Mirko llić $^{2}$ \\ 'Department of Epidemiology, Faculty of Medicine, University of Niš, Serbia \\ ${ }^{2}$ Institute of Public Health Niš, Serbia
}

\section{SUMMARY}

The aim of the study was to assess recent changes in lung cancer incidence and mortality trends in the male and female population in Southeastern Serbia, in the period 1999-2008. Data used for analyses were provided by the Cancer Registry of the Institute for Public Health, Niš. Incidence and mortality trends were based on crude and age-standardized incidence and mortality rates for the period 1999-2008. Standardized rates were calculated by the direct method of standardization (per 100,000), using the world population as the standard. Statistical significance was checked on the basis of correlation coefficient (r) for probability (p) on the level of 0.05 . A total of 3,128 new cases and 2,327 deaths from lung cancer were registered (males/females ratio is $4: 1$ ). In males, the crude (107.94) and the age-standardized incidence rate (59.88) were four-fold higher than in females (27.10 and 14.21). In males, the crude mortality rate was four-fold higher than in females ( 80.61 vs. 19.87), while the age-standardized mortality rate was four and a half higher than in females ( 43.78 vs. 9.54). Lung cancer incidence trend, based on crude and age-standardized incidence rates, in females was increasing while in males was decreasing. Lung cancer mortality trends, based on crude and age-standardized incidence rates, were increasing in both sexes. Registration of unfavourable incidence and mortality trends of lung cancer indicate failure in primary and secondary prevention in the past. It is thus of vital importance to provide much intensive and comprehensive activities for primary and secondary prevention of lung cancer in the future, including education and rigorous tobacco control as well.

Key words: epidemiology, lung cancer, incidence, mortality

Address for correspondence: B. Kocić, Department of Epidemiology, Faculty of Medicine, University of Niš, Blvd. dr Z. Djindjić 81,18000 Niš, Serbia. E-mail: biljaizzz@yahoo.com

\section{INTRODUCTION}

Smoking is the principal cause of lung cancer, it is estimated to be responsible for 85 per cent of all types of this cancer. The link between tobacco and lung cancer was established more than fifty years ago (1), and incidence rates closely reflect past smoking prevalence with a time lag of approximately $20-30$ years (2-4).

There is estimated to be more than one billion smokers in the world, which is about a quarter of adults. Smoking prevalence is higher in men than in women in most countries worldwide. In 2006 , an estimated $41 \%$ of men and $9 \%$ of women were smokers, though this varied considerably by country and age. In many developing countries, the consumption of cigarettes is increasing rapidly in both sexes due to population growth and the increased targeted tobacco marketing in these areas (especially at young people) $(4,5)$. Worldwide, the number of smokers is continuing to rise, and without intervention this will lead to large increase in the incidence of lung cancer in the coming decades $(4,5)$.

Lung cancer is the most common cancer in the world. In 2008, there were 1.61 million new cases diagnosed which represented $12.7 \%$ of all new cancer cases (2). The majority of cases now occur in the developing countries (55\%). It is still also the most common cause of death, with 1.38 million deaths $(18.2 \%$ of the total) reported in 2008 .

There is twenty-fold variation in male lung cancer incidence and nineteen-fold variation in lung cancer mortality across the regions of the world. In 2008, the highest incidence and mortality rates were seen in Central and Eastern Europe (56.5 and 50.5), Southern Europe (48.9 and 42.4), and Northern America (48.5 and 37.9) (2). The proportion of men smoking is also high in this European region, with Russia, Ukraine and Belarus having some of the highest age-standardized smoking prevalence estimates in the world (with $70 \%, 64 \%$, and $64 \%$ of men currently smoking any form of tobacco, respectively) (5).

Lung cancer incidence is more than twice as high in men than in women worlwide (rate ratio $2.5: 1.0$ ). In females, incidence rates are generally lower, however, there is forty-fold variation in female lung cancer incidence and thirty-fold variation in lung cancer mortality, worldwide. In 2008, the highest incidence and mortality rates were seen in Northern America (35.8 and 24.2), Northern Europe (23 and 18.8), Australia and New Zealand (19.9 and 14.6), and Eastern Asia (19.9 and 16.3) (2).

According to 2008 data, lung cancer in Serbia is the leading type of cancer among men with malignant diseases $(21.3 \%$ of all cancers) as well as in cancer deaths (31.3\% of all cancers) (6). It ranks 3 rd in women with malignant diseases ( $8.1 \%$ of all cancers) and 2 nd in cancer deaths (12.1\% of all cancers) (6).

The aim of the study was to assess recent changes in lung cancer incidence and mortality trends in Southeastern part of Serbia (Nisava District and Toplica District), in the period 1999-2008 by analysing the crude and age-standardized incidence and mortality rates of this disease in the male and female population.

\section{MATERIALS AND METHODS}

Data used for analyses were provided by the Cancer Registry of the Institute for Public Health, Niš. Information sources concern- 
ing new cancer cases/deceased cases are registries of the oncology institutes, oncology dispensaries, oncology clinics, hospitals and out-patients health institutions, pathohistology/citology, hematology and other laboratories, death reports, health insurance funds, and targeted research. Incidence and mortality trends were described for both sexes, based on crude and age-standardized incidence and mortality rates for the period 1999-2008. Standardized rates were calculated by the direct method of standardization (per $100,000)$, using the world population as the standard. Statistical significance was checked on the basis of correlation coefficient (r) for probability (p) on the level of 0.05 .

For the calculation of incidence and mortality rates, the population denominator data was obtained from the 1991 and 2002 national censuses and from the estimates published by the Republic Institute of Statistics for inter-census years. In 2008, there were 471,156 inhabitans (232,950 males; 238,206 females) of Nisava and Toplica Districts.

\section{RESULTS}

In the study period, a total of 3,128 new cases of lung cancer were registered. A total of 2,492 (79.67\%) cases occured in males and $636(20.33 \%)$ in females.

The crude incidence rate for the period of observation in males was $107.94 / 100,000$, while the age-standardized incidence rate was 59.88/100,000. The highest age-standardized incidence rate in males was registered in 2001 (72.10), while the lowest rate was reported in 2007 (48.50) (Fig. 1).

During the entire period of observation, the crude incidence rate in females was $27.10 / 100,000$, while the age-standardized incidence rate was 14.21/100,000. The highest age-standardized incidence rate in females was registered in 2008 (19.30), while the lowest rate was found at the beginning of the observation period, in 1999 (11.50) (Fig. 1).

In the study period, a total of 2,327 deaths due to lung cancer were registered. A total of 1,860 (79.93\%) cases occured in males and $467(20.07 \%)$ in females.

The crude mortality rate for the observation period in males was $80.61 / 100,000$, while the age-standardized mortality rate was $43.78 / 100,000$. The highest age-standardized mortality rate in males was registered in 2008 (46.70), while the lowest rate was observed in 2004 (38.10) (Fig. 2).

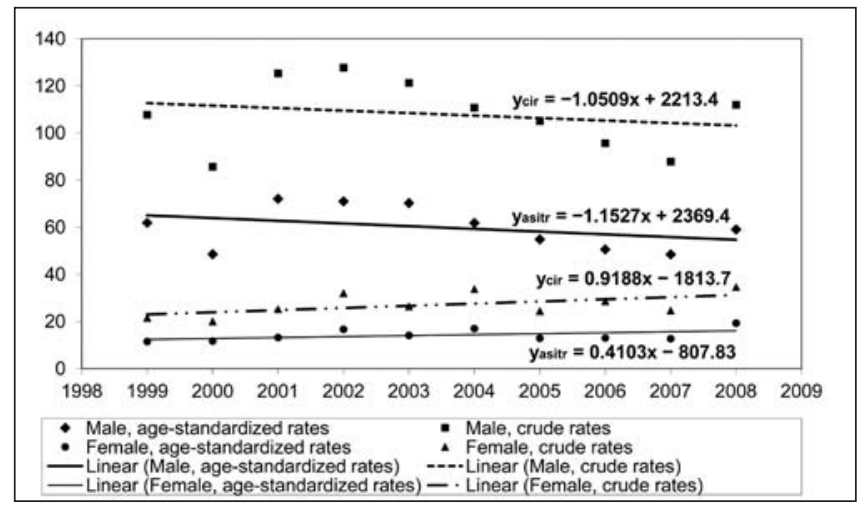

Fig. 1. Lung cancer incidence trend in males and females in Southeastern Serbia, in the period 1999-2008.
During the entire period of observation, the crude mortality rate in females was $19.87 / 100,000$, while the age-standardized mortality rate was $9.54 / 100,000$. The highest age-standardized mortality rate in females was registered in 2008 (12.30), while the lowest rate was found at the beginning of the observation period, in 2000 (7.0) (Fig. 2).

A decreasing tendency of linear trend of lung cancer incidence in males based on crude and age-standardized incidence rates was registered (Fig. 1):

$$
\begin{aligned}
& Y_{\text {cir }}=-1.0509 x+2213.4 ; r^{2}=0.1467 ; r=-0.380 ; p>0.05 \\
& Y_{\text {asitr }}=-1.1527 x+2369.4 ; r^{2}=0.1447 ; r=-0.212 ; p>0.05
\end{aligned}
$$

There was an increasing tendency of linear trend of lung cancer incidence in females based on crude and age-standardized incidence rates (Fig. 1):

$$
\begin{aligned}
& \mathrm{Y}_{\text {cir }}=0.9188 \mathrm{x}-1813.7 ; \mathrm{r}^{2}=0.3089 ; \mathrm{r}=0.556 ; \mathrm{p}>0.05 \\
& \mathrm{Y}_{\text {asitr }}=0.4103 \mathrm{x}-807.83 ; \mathrm{r}^{2}=0.2314 ; \mathrm{r}=0.481 ; \mathrm{p}>0.05
\end{aligned}
$$

An increasing tendency of linear trend of lung cancer mortality in males based on crude and age-standardized mortality rates for the period of observation was registered (Fig. 2):

$$
\begin{aligned}
& Y_{\text {cmr }}=1.1097 \mathrm{x}-2142.7 ; \mathrm{r}^{2}=0.2636 ; \mathrm{r}=0.285 ; \mathrm{p}>0.05 \\
& \mathrm{Y}_{\text {asmrt }}=0.2667 \mathrm{x}-490.49 ; \mathrm{r}^{2}=0.081 ; \mathrm{r}=0.513 ; \mathrm{p}>0.05
\end{aligned}
$$

There was an increaseing tendency of linear trend of lung cancer mortality in females based on crude and age-standardized mortality rates for the observation period (Fig. 2):

$$
\begin{aligned}
& \mathrm{Y}_{\mathrm{cmr}}=1.1048 \mathrm{x}-2193.7 ; \mathrm{r}^{2}=0.6582 ; \mathrm{r}=0.811 ; \mathrm{p}<0.05 \\
& \mathrm{Y}_{\text {asmrt }}=0.4497 \mathrm{x}-891.43 ; \mathrm{r}^{2}=0.3826 ; \mathrm{r}=0.619 ; \mathrm{p}<0.05
\end{aligned}
$$

\section{DISCUSSION}

Countries are at different stages in the lung cancer epidemic as a result of different history of tobacco consumption and the long latency period between smoking and lung cancer development (7).

Hungary has the highest age-standardized incidence rate of lung cancer in males (80.9), followed by Armenia (77.5) and Poland (71.2). European lung cancer mortality rates vary markedly with age-standardized rates for Hungarian men (73.5) more than three and a half times higher than those for Swedish men (19.4) $(2,7)$.

The USA has the highest age-standardized incidence rate of lung cancer in women (36.2), followed by Denmark (34.6), Canada (32.4), and Hungary (30.7). Denmark has the highest age-standardized mortality rate of lung cancer in females (30),

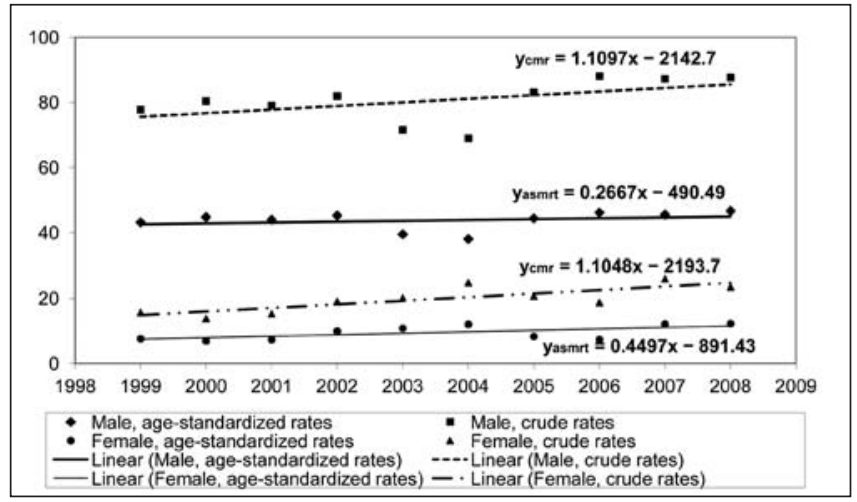

Fig. 2. Lung cancer mortality trend in males and females in Southeastern Serbia, in the period 1999-2008. 
followed by Iceland (26.5), the Netherlands (22.1), Canada (24.9), and the USA (24.1) (2).

Three out of 10 EU citizens aged 15 and over state that they smoke: a quarter (26\%) smokes daily and $5 \%$ occasionally ( 8$)$. The proportion of smokers is the highest in Greece (42\%), followed by Bulgaria (39\%), Latvia (37\%), Romania, Hungary, Lithuania, the Czech Republic, and Slovakia (all 36\%). Respondents in Slovenia (22\%), followed by those in Sweden and Finland (both $25 \%$ ) are the least likely to be smokers. More men than women say they smoke every day ( $32 \%$ vs. $21 \%)$, although a similar proportion of men and women say they only smoke occasionally (6\% and 5\%, respectively). Furthermore, women are more likely to have never smoked ( $55 \%$ vs. $37 \%$ ), while men are more likely to have quit smoking ( $26 \%$ vs. $19 \%$ ). Fourteen percent of non-smokers and $23 \%$ of smokers are exposed to other people's tobacco smoke at home on an almost daily basis. Home exposure to environmental tobacco smoke (ETS, also called second-hand smoke or passive smoke) is the lowest in Finland and Sweden - not more than $5 \%$ of Finns and Swedes are regularly exposed to other people's tobacco smoke at home. Lithuanians, Cypriots, Greeks, and Bulgarians are six time more likely to be exposed to ETC at home (29-30\%). Exposure of non-smokers to ETC is the highest in Cyprus (31\%), Lithuania and Greece (both 28\%), and the lowest in Finland (2\%) and Sweden (3\%). The proportion of smokers who expose others to tobacco smoke at home ranges from $8 \%$ in Finland and $16 \%$ in Sweden to half of the smokers in Poland (53\%), Greece (51\%), Bulgaria (50\%), and Denmark $(49 \%)$. One fifth of respondents working outside the home are exposed to tobacco smoke at their workplace on a daily basis. In Greece, 6 out of 10 working respondents are exposed, while 9 out of 10 in Sweden, the UK, and Finland are never, or hardly ever, exposed to tobacco smoke at work (8).

Among the former Yugoslavia countries, Serbia with the highest male cancer incidence and mortality rates (66.1 and 60.1) is followed by Croatia (60 and 56.3), FYR Macedonia (57.8 and 48.9), Montenegro (56.5 and 50.1), Slovenia (54.7 and 47.4), and Bosnia and Herzegovina (41.7 and 37) (2). Also, Serbia, with the highest female lung cancer incidence and mortality rates (18.5 and 16.4) is followed by Montenegro (16.7 and 15.5), Slovenia (16.3 and 13.2), Croatia (13.9 and 12.3), Bosnia and Herzegovina (9.5 and 8.2), and FYR Macedonia (7.7 and 7) (2).

Similar to our findings, higher incidence rates in males than in females were registered in Central Serbia (6). In the UK in the $1950 \mathrm{~s}$, the male/female ratio for lung cancer cases was $6: 1$, but with decreasing male rates and increasing female rates, the ratio is now $1.3: 1$ (9). Higher incidence rates in males than in females were registered in Belgium (57.1 vs. 17.5), the Netherlands (47.4 vs. 27.2 ), Denmark (43.3 vs. 34.6 ), Norway (35.3 vs. 24.7 ), and Ireland (37.9 vs. 24.4) (2).

Over the studied period, significant differences in lung cancer incidence among regions of Serbia were found, with very high rates in the population of Southeastern part of Serbia. For example, in the middle of the period, in 2003, lung cancer incidence rate in men ranged from 32.3/100,000 population in Pirotski District to $79.9 / 100,000$ population in Belgrade District, while in Nisava District and Toplica District was very high, 70.3/100,000 and $52.2 / 100,000$ population, respectively (10). Lung cancer incidence rate in women ranged from 5.8/100,000 population in Zajecarski District to $24.8 / 100,000$ population in Belgrade District. Female lung cancer incidence rate in Nisava District and Toplica District was $14.1 / 100,000$ and $18.6 / 100,000$ population, respectively. There are numerous reasons for unfavourable incidence and mortality trends of lung cancer in the population of Southeastern part of Serbia over the studied period. A lack of organized programmes for primary and secondary prevention and failure in tobacco control may partially explain such situation. Moreover, this part of Serbia is poor and socio-economically underdeveloped region. Anyway, incidence and mortality rates in males and females are higher in the population of Serbia than those in the former Yugoslavia countries. Out of all malignancies analyzed in The Burden of Diseases and Injuries in Serbia, lung cancer is at the top (11). In 1999-2005, the standardized incidence rate for lung cancer in Central Serbia increases by $15.5 \%$ in men and by $23.7 \%$ in women (12). In the period 1997-2007, lung cancer mortality rate in men increases by $15 \%$, and in women by $43.8 \%$ (13). In the period 1994-2003, tobacco smoking status of lung cancer patients in Serbia was: smokers, ex-smokers, and nonsmokers accounted for $70.3 \%, 17 \%$, and $12.6 \%$, respectively (14).

Smoking is still widely accepted social behaviour in Serbia. In 2006 , the proportion of smokers among adults was $33.6 \%$ (38.1\% of men and $29.9 \%$ of women) (15). Most smokers belong to the 33-44 years age group (46.9\%), unclassified people (36.7\%), in urban settlements (36.7\%), who have secondary school education (39.9\%). In 2006, over three fifths of adult population (61.7\%) in Serbia were exposed to tobacco smoke at home, and $44.9 \%$ at work, which is an improvement compared to the year 2000 (65.7\% and $55.4 \%$, respectively) $(15,16)$. Exposure to tobacco smoke at home was higher for women $(62.1 \%)$, while men were more exposed at work (49\%). Over a half of the Serbian population $(57.5 \%)$ were aware of deleterious consequences of smoking and exposure to tobacco smoke. Out of all adult smokers only $1 \%$ stated to have used counselling service to help them to quit smoking. Out of the total number of smokers $37.1 \%$ stated they wanted to quit smoking: more women (39.9\%) than men (34.4\%). People aged 35-44 are the ones most acutely aware of deleterious consequences of smoking/tobacco smoke to health (15).

Over a half of school children in Serbia aged 13-15 years $(54.7 \%)$ have already smoked cigarettes, and one in six $(16.3 \%)$ currently smokes (17). Approximately one third (31.3\%) have lit their first cigarette before they turned 10 suggesting a high potential for use of tobacco later in life and potentially high prevalence of tobacco-induced diseases. Young people are greatly exposed to secondary tobacco smoke in their own homes $(96.4 \%$ of nonsmokers and $98.4 \%$ of current smokers) and in public (87\% of non-smokers and $96.5 \%$ of current smokers) (17).

The results of survey conducted among the first grade high school students (aged 16) in the regional centres (Belgrade, Niš and Novi Sad) in 2008 show that boys started smoking earlier than girls; $19.5 \%$ of boys and $14.5 \%$ of girls smoked their first cigarette at the age of 13 or earlier (18). In the last 30 days, $13.9 \%$ of students (approximately the same number of boys and girls) have smoked daily - at least one cigarette per day. The smallest number of everyday smokers is among gymnasium students (9.4\%) compared to students from vocational technical schools $(15.6 \%)$ and vocational handicraft schools (14.3\%). In rural areas, there is the highest percentage of daily smokers. Every fifth adolescent (19.4\%) has smoked during the last month, at least one cigarette per day. Regional distribution indicates that a 
higher number of young daily smokers is in Vojvodina (17.0\%), Belgrade (14.7\%), and Central Serbia (12.3\%) (18). It is important to intensify the efforts to stop young people from even adopting the habit, and support those trying to quit.

Measures for tobacco control in Serbia, such as legislative measures, ban on tobacco advertising, and restriction on smoking in public places resulted in decrease of smoking prevalence. In 2006 , smoking among adults was reduced by $6.9 \%$ in comparison with the year $2000(33.6 \%)$. By gender, smoking in men was reduced by $9.8 \%$ (from $47.9 \%$ in 2000 to $38.1 \%$ in 2006 ) and by $3.8 \%$ in women (from $33.7 \%$ in 2000 to $29.9 \%$ in 2006) (15, 16). Nevertheless, the prevalence of smokers in Serbia, especially among young men, is one of the highest in Europe. High prevalence of smokers, together with aging of population, may increase the lung cancer burden in Serbia in upcoming years.

The results of a cross-sectional, population-based national representative household survey in Serbia indicated that smoking experience and quitting are predicted by socio-economic status and gender (19). The results showed that educated women were more prone to smoking (university degree: OR $1.53 ; 95 \%$ CI 1.26-1.86), whereas for men the opposite was observed (university degree: OR 0.72 ; 95\% CI $0.60-0.86$ ). Education was also "pro-quitting" factor (university degree: OR 1.46; 95\% CI 1.07-1.99 for women; university degree: OR 1.61; 95\% CI $1.23-1.80$ for men). Wealth status was gradually more important for women to quit smoking while the rich men were more likely to quit (OR 1.45; 95\% CI 1.09-1.93).

Additional evidence for the significant inverse association between the indicators of socio-economic status and lung cancer risk comes from a recent case-control study involving 3,403 cancer cases and 3,670 controls which was conducted in Central European countries (Czech Republic, Hungary, Poland, Romania, Slovakia), Russia, and in the UK (20). The odds ratio of male lung cancer for blue collar occupations compared to white collar occupations was 1.37 (95\% CI 1.15-1.62), that for low education compared to high education (analysis restricted to Central European countries) was 1.35 (95\% CI 1.03-1.77). No such effects were observed in women.

Patterns of educational differences in lung cancer mortality differ strongly by population and gender as in work of Mackenbach JP, et al. (2004) (21), and it is now confirmed across a broader set of populations, including France, Slovenia, and Basque region (22). This reflects differences in the spread of the smoking epidemic (23), in which higher smoking rates are first observed among subjects of higher socio-economic status. The smoking epidemic was less advanced in Spain and Slovenia, where higher smoking prevalence among women with high education but reverse patterns among men were found. In contrast, this epidemic was in its final stage in Nordic countries, Belgium, and Switzerland, with higher tobacco consumption among women and men with low education attainment. France and Italy showed an intermediate situation with no clear association between education and smoking prevalence among women $(24,25)$. Male-female smoking differences by education are less pronounced in Nordic countries or Belgium than in more southern countries, reflecting the clear north-south contrast observed among women for socioeconomic inequalities in smoking.

A detailed analysis was made of the malignant cancer incidence rates for the Czech Republic from 1973-1989, concentrating on time trends in five-year age groups (26). The results were compared with the trend of age-standardized incidence (Standardized Incidence Ratio, SIR). Lung cancer in men - the SIR trend is insignificant, there is an increase in incidence in the 45 to 64 years age group and a decrease in the 70 to 79 years age group (26). Among men, the lung cancer death rates in 1989 for the Czech Republic (75.8/100,000 age-adjusted to the world standard), Hungary (74.0), Poland (69.4), and Slovakia (68.7) ranked among the highest in Europe, the trends by country largely reflecting the varied prevalence and duration of smoking in previous decades (27). The patterns of increases in cigarette sales during the 1960s and 1970s were different by country, and, in the 1980s, the consumption in Hungary and Poland exceeded 3,000 pieces of cigarettes/year per adult (age 15 years and older) (27).

Concerning causes of mortality, a tobacco-related mortality among Polish men has increased more than 50\% from the 5-year period from 1965-1969 to the period 1990-1994 (28). The analysis for women shows much lower rates compared with men. When comparing the middle age group with the overall population, it is interesting to find a faster increase in tobacco-related mortality rates for Polish men and for Swedish women in the age group of 45-64 years than in the overall group. Swedish men have reduced their smoking habit strongly and far more than Polish men (17 and 42\%, respectively in 1999). Concerning the pattern of tobacco use, it is obvious that Swedish and Polish women during the last decades have had the same and slowly decreasing smoking prevalence (21 and 23\%, respectively in 1999) (28). Male lung cancer mortality was constant in Sweden during the last two decades, which was contrary to the trend in Poland with a long period of increase followed by a slow decrease during the last years (29). Lung cancer mortality for women in both countries was on a continuous increase and the rate was exactly the same. The premature mortality from lung cancer in Sweden in the age group of 22-44 years is higher for women than for men. It is obvious that the best way to control the lung cancer epidemic is to reduce smoking prevalence in the population (29).

In the EU overall, lung cancer mortality in men declined from 55.4 in the late 1980 s to $49.2(-11 \%)$ in 1997 , and to $44.4(-10 \%)$ in $2002(30,31)$. During the period from 1994-2004, the greatest annual lung cancer mortality changes were observed in Italy $(-3.9 \%)$, Finland $(-3.4 \%)$, the UK $(-3.3 \%)$, and the Netherlands $(-3.3 \%)(31)$. Decreasing lung cancer incidence and mortality trends are the result of decreased prevalence of male smokers in Western Europe during the last decades.

In the UK, between 1993 and 2008 male lung cancer incidence rates decreased by almost a third (32\%), while female rates increased by $11 \%$. For males and females combined, the lung cancer incidence decreased by $15 \%$ (20). Longer trends in lung cancer incidence rates for males in the UK have fallen by $47 \%$ from 1975 to 2008, while female lung cancer incidence rates have risen by $71 \%$ (9).

On the contrary, there is an increasing lung cancer trend in males and females in France, Spain, and Portugal. In countries of Northern Europe (Denmark, Finland), a decrease in lung cancer incidence trend in males has been registered while in females it is increasing (2).

In the USA, from 1973 to 2006 , lung cancer age-adjusted incidence rates increased by $22.5 \%$ (17.0\% in males, $146.9 \%$ in females) (32). The number of deaths due to lung cancer has in- 
creased by $4.3 \%$ from 1999 to 2006 . In 2006, the greatest number of lung cancer deaths were among white males and the lowest number among black females (33). It has been shown that rises and declines in lung cancer incidence and mortality rates parallel past trends of cigarette smoking.

In Alberta, Canada, from 1988 to 2008, male lung cancer incidence and mortality rates decreased (by an average annual reduction of $1.2 \%$ and $1.4 \%$, respectively). Female lung cancer incidence and mortality rates increased significantly between 1988 and 1999 (an average annual increase of 3.2\% and 3.7\%, respectively, was reported) (34). From 1999 to 2008, female lung cancer incidence and mortality rates increased (an average annual increase of $1.1 \%$ and $1.4 \%$, respectively, was observed) (34).

\section{CONCLUSION}

Registration of unfavourable incidence and mortality trends in lung cancer indicate failure in primary and secondary prevention in the past. It is thus of vital importance to implement a comprehensive primary and secondary prevention of lung cancer in the future, including education and rigorous tobacco control as well. It is important to intensify the efforts to stop young people from starting to smoke, and support those that try to quit. Health professionals have to play a more active role in tobacco control.

\section{Acknowledgements}

This work was supported by grants, No III 46013 and No III 43014, from the Ministry of Sciences and Technological Development of the Republic of Serbia.

\section{REFERENCES}

1. Doll R, Hill AB. Smoking and carcinoma of the lung; preliminary report. Br Med J. 1950 Sep 30;2(4682):739-48.

2. International Agency for Research on Cancer; World Health Organization. GLOBOCAN 2008: the GLOBOCAN project [Internet]. Lyon: International Agency for Research on Cancer; 2010 [cited 2012 Dec 6]. Available from: http://globocan.iarc.fr/.

3. Boyle P, Levin B, editors; International Agency for Research on Cancer; World Health Organization. World cancer report 2008. Lyon: IARC; 2008

4. World Health Organization. WHO report on the global tobacco epidemic, 2009: implementing smoke-free environments. Geneva: WHO; 2009

5. World Health Organization. WHO report on the global tobacco epidemic, 2008: the MPOWER package. Geneva: WHO; 2008.

6. Institute of Public Health of Serbia "Dr. Milan Jovanović - Batut". Cancer incidence and mortality in Central Serbia 2008. Report, no. 10. Belgrade: Cancer registry of Central Serbia; 2010.

7. Ferlay J, Parkin DM, Steliarova-Foucher E. Estimates of cancer incidence and mortality in Europe in 2008. Eur J Cancer. 2010 Mar;46(4):765-81.

8. European Commission. Survey on tobacco: analytical report. Flash Eurobarometer series, no. 253. The Gallup Organization; 2009.

9. Cancer research UK. Lung cancer incidence statistics [Internet]. London: Cancer research UK; 2012 [cited 2012 Dec 6]. Available from: http:// info.cancerresearchuk.org/cancerstats/types/lung/incidence/.

10. Institute of Public Health of Serbia “Dr. Milan Jovanović - Batut". Cancer incidence and mortality in Central Serbia 2003. Report, no. 5. Belgrade: Cancer registry of Central Serbia; 2006.

11. Atanasković-Marković Z, Bjegović V, Janković S, Kocev N, Laaser U, Marinković J, et al. The Burden of disease and injury in Serbia. Belgrade: Ministry of Health of the Republic of Serbia; 2003.

12. Cancer incidence and mortality in Central Serbia - 1999-2005. Belgrade: Institute of Public Health of Serbia "Dr. Milan Jovanović - Batut"; 2007.
13. Grozdanov J, editor. Health of population of Serbia: analytical study 1997-2007 [CD-ROM]. Belgrade: Institute of Public Health of Serbia "Dr. Milan Jovanović - Batut"; 2009.

14. Pešut D, Basara HZ. Cigarette smoking and lung cancer trends in Serbia - a ten-year analysis. Med Pregl. 2006 May-Jun;59(5-6):225-9.

15. Ministry of Health of the Republic of Serbia. National health survey Serbia, 2006. Key findings. Belgrade: Ministry of Health of the Republic of Serbia; 2007.

16. Ministry of Health of the Republic of Serbia. National health survey Serbia, 2000. Belgrade: Ministry of Health of the Republic of Serbia; 2001.

17. Dzelatovic A, Dimitrijevic-Tanaskovic L. Global tobacco youth survey, Republic of Serbia 2003. Belgrade: National commission for smoking prevention of Ministry of Health of the Republic of Serbia; 2005.

18. Ministry of Health of the Republic of Serbia; Institute of Public Health of Serbia "Dr. Milan Jovanović - Batut"; ESPAD. European Survey on the use of Alcohol and Other Drugs among young people in Serbia 2008. Belgrade: Ministry of Health of the Republic of Serbia; 2009.

19. Djikanovic B, Marinkovic J, Jankovic J, Vujanac V, Simic S. Gender differences in smoking experience and cessation: do wealth and education matter equally for women and men in Serbia? J Public Health (Oxf). 2011 Mar;33(1):31-8.

20. Hrubá F, Fabiáová E, Bencko V, Cassidy A, Lissowska J, Mates D, et al. Socioeconomic indicators and risk of lung cancer in Central and Eastern Europe. Cent Eur J Public Health. 2009 Sep;17(3):115-21.

21. Mackenbach JP, Huisman M, Andersen O, Bopp M, Borgan JK, Borrell $\mathrm{C}$, et al. Inequalities in lung cancer mortality by the educational level in 10 European populations. Eur J Cancer. 2004 Jan;40(1):126-35.

22. Menvielle G, Kunst AE, Stirbu I, Strand BH, Borrell C, Regidor E, et al. Educational differences in cancer mortality among women and men: a gender pattern that differs across Europe. Br J Cancer. 2008 Mar 11;98(5):1012-9.

23. Lopez AD, Collishaw NE, Piha T. A descriptive model of the cigarette epidemic in developed countries. Tob Control. 1994;3(3):242-7.

24. Giskes K, Kunst AE, Benach J, Borrell C, Costa G, Dahl E, et al. Trends in smoking behaviour between 1985 and 2000 in nine European countries by education. J Epidemiol Community Health. 2005 May;59(5):395-401.

25. Huisman M, Kunst AE, Mackenbach JP. Educational inequalities in smoking among men and women aged 16 years and older in 11 European countries. Tob Control. 2005 Apr;14(2):106-13.

26. Fiala J. The incidence of cancer in the Czech Republic from 1973 to 1989: cancers with non-parallel trends in age groups. Cent Eur J Public Health. 1996 Sep;4(3):157-63.

27. Kubík A, Pleško I. Trends in cigarette sales and lung cancer mortality in four central European countries. Cent Eur J Public Health. 1998 Feb;6(1):37-41.

28. Wramner B, Pellmer K. Tobacco-related mortality following the PetoLopez epidemiological model used in international public health comparison. Cent Eur J Public Health. 2002 Dec;10(4):142-5.

29. Wramner B, Zlatoński W, Pellmer K. Premature mortality in lung cancer as an indicator of effectiveness of tobacco use prevention in a gender perspective - a comparison between Poland and Sweden. Cent Eur J Public Health. 2001 May;9(2):69-73.

30. Levi F, Lucchini F, Negri E, La Vecchia C. Continuing declines in cancer mortality in the European Union. Ann Oncol. 2007 Mar;18(3):593-5.

31. Karim-Kos HE, de Vries E, Soerjomataram I, Lemmens V, Siesling S, Coebergh JW. Recent trends of cancer in Europe: a combined approach of incidence, survival and mortality for 17 cancer sites since the 1990s. Eur J Cancer. 2008 Jul;44(10):1345-89.

32. National Cancer Institut. Surveillance epidemiology and end results. Previous version: SEER cancer statistics review, 1975-2006 [Internet]. Bethesda: National Cancer Institut [cited 2012 Dec 6]. Available from: http://seer.cancer.gov/csr/1975 2006/.

33. Centers for Disease Control and Prevention. National vital statistics system. Mortality data [Internet]. Atlanta: Centers for Disease Control and Prevention; 2012 [cited 2012 Dec 6]. Available from: http://www. cdc.gov/nchs/deaths.htm.

34. Hatcher J, editor. Cancer in Alberta: 2008 report on cancer statistics in Alberta. Edmonton: Alberta Health Services; 2010. 